\title{
RECENT DEVELOPMENTS IN CLOUD PHYSICS
}

$\mathrm{T}$ HE summer meeting of the Royal Meteorological Society, held in Glasgow during July 3-5, began with a lively and well-attended discussion on cloud physics. The meeting, which was held in the Department of Natural Philosophy, University of Glasgow, with Prof. P. I. Dee in the chair, was delighted to welcome Prof. C. T. R. Wilson, now in his eighty-ninth year.

Dr. B. J. Mason (Imperial College of Science and Technology, London) began by describing the results of some recent experiments, carried out in collaboration with J. Hallett, E. J. Langham and J. Maybank, on the supercooling and nucleation of water and on the growth of ice crystals from the vapour. Observations on the freezing of large numbers of droplets of distilled water, ranging from $10 \mu$ to $1 \mathrm{~cm}$. in diameter and suspended at the interface of two immiscible liquids in order to avoid the nucleating effects of solid surfaces, had established proportionality between the logarithm of the droplet volume and its freezing temperature for a constant rate of cooling. Such a relationship appeared to characterize the heterogeneous nucleation of water droplets containing small foreign nuclei, and is probably associated with the fact that the ice-nucleating ability of atmospheric aerosols increases logarithmically with decreasing temperature. Dr. Mason went on to describe very recent experiments which had been successful in purifying water to such an extent that droplets could be regularly supercooled to temperatures ranging from $-41^{\circ}$ C. for $1-\mu$ droplets to $-33^{\circ} \mathrm{C}$. for drops $1 \mathrm{~mm}$. in diameter, at which freezing occurred spontaneously without the aid of foreign nuclei. The empirical relationship between droplet volume and nucleation temperature, which differed from that representing heterogeneous nucleation, showed good agreement with theory.

Photographs taken of freezing droplets revealed that, in some cases, solidification was accompanied by rupture of the ice surface and the liberation of a number of small ice splinters. This suggests a mechanism by which the numbers of ice crystals in clouds may be rapidly increased.

In an attempt to discover the nature and origin of atmospheric ice nuclei, tests had been made of the nucleating ability of various types of soil particles and mineral dusts, and had revealed that a number of silicate minerals such as kaolinite, microcline and some of the micas were effective at temperatures greater than $-15^{\circ} \mathrm{C}$. but that the more common silicates were relatively inactive. However, several types of nucleus became more effective once they had been involved in ice-crystal formation. Thus when ice crystals, formed on various silicate particles initially active only below about $-20^{\circ} \mathrm{C}$., were allowed to evaporate by warming them to very near $0^{\circ} \mathrm{C}$. in a dry atmosphere, they left behind nuclei which were thereafter effective at temperatures as high as $-5^{\circ} \mathrm{C}$. Dr. Mason suggested that although most of the particles carried up from the ground can initially form ice crystals only at the low temperatures associated with the high eirrus clouds, when the crystals evaporate they may leave behind pre-activated nuclei, which may later seed lower clouds at temperatures only a few degrees below zero. This may explain why the tops of shower clouds sometimes show signs of glaciation at temperatures as high as $-6^{\circ} \mathrm{C}$, although nuclei active at these temperatures are rarely detected in surface air.

Finally, Dr. Mason used a series of photographs to illustrate the growth of ice crystals on a fine fibre running vertically through the centre of a watervapour diffusion chamber. Clear-cut changes of crystal habit-from hexagonal plates $\rightarrow$ needles $\rightarrow$ hollow prisms $\rightarrow$ plates $\rightarrow$ stellar dendrites $\rightarrow$ plates $\rightarrow$ prisms-took place along the length of the fibre, over which the temperature varied from $0^{\circ} \mathrm{C}$. to $-40^{\circ} \mathrm{C}$. These closely imitated the changes occurring in natural snow crystals. That the relative growthrates of the basal and prism faces of ice crystals should change so abruptly and so often is very puzzling, but these experiments had clearly shown that the temperature and not the supersaturation of the environment is primarily responsible. The supersaturation is, however, important in determining the growth-rates of the crystals and the development of dendritic forms.

Recent measurements of condensation nuclei, cloud particles and rain, made from aircraft of the Meteorological Research Flight, Farnborough, were described by Mr. R. J. Murgatroyd (Meteorological Office). Raindrops measured at the surface commonly have diameters of $0.5-5 \mathrm{~mm}$., and occur in concentrations of $0 \cdot 1-1 \cdot 0$ per litre, whereas condensetion nuclei have diameters of $0.01 \mu$ or more and concentrations of $10^{6}-10^{7}$ per litre near cloud base. One of the main problems in cloud physics is to trace how raindrops develop after condensation on these nuclei.

Measurement of the total numbers of condensation nuclei from an aircraft by means of a Nolan-Pollak photo-electric counter indicated that concentrations over the land, particularly near industrial areas, are considerably greater than over the sea. Numbers decrease rapidly with height, the profile of concentration in the vertical being mainly determined by atmospheric stability. Cloud droplets, which were measured by impaction on magnesium oxide or oilcoated slides, are usually $10-30 \mu$ in diameter with concentrations of $10^{5}-10^{6}$ per litre, so that only a fraction of the available condensation nuclei are apparently involved in the production of cloud. The most active will be the larger hygroscopic nuclei, probably of sodium chloride, and Mr. Murgatroyd described how the concentrations and sizes of salt nuclei are determined by collecting them on slides coated with a gelatine impregnated with silver nitrate. These particles are mainly in the range $0 \cdot 5$ $10 \mu$ in diameter with concentrations of $10^{2}-10^{3}$ per litre, and their vertical distribution is again controlled by atmospheric stability and the nature of their source. In these concentrations they are likely to be associated with only the largest cloud droplets, and it is these which will probably grow to raindrop size by coalescence.

Precipitation elements (greater than $100 \mu$ in diameter) were sampled by exposing a thin aluminium foil from the aircraft, and measuring the 
indentations produced by the particles on impact, a technique developed by the Mechanical Engineering Department of the Royal Aireraft Establishment, Farnborough. It has been found that small cumulus clouds, a few thousand feet thick, contain droplets about $100 \mu$ in diameter in concentrations of $0.1-$ 1.0 per litre, which is of the same order as the concentration of raindrops at the surface. Examples were also given of the way raindrop sizes vary with height in layer clouds at temperatures above freezing, particles growing to raindrop size by overtaking and amalgamating with smaller droplets falling at slower speeds. The same technique is also being used to examine the development of rainfall by the Bergeron mechanism, which involves the ice-phase. Crystals in cirro stratus cloud rarely exceed $250 \mu$ in diameter, but in alto stratus and nimbo stratus snow flakes of 1-2 $\mathrm{mm}$. diameter, increasing in size as they fall, are found. There is some size decrease as they melt at the freezing-level and then further increase during the rain stage below. Conditions in cumulo nimbus clouds are much more complex, liquid water drops often being found at temperatures of $-10^{\circ} \mathrm{C}$. to $-30^{\circ} \mathrm{C}$. The particles are larger and greater in number than in frontal clouds. In each case a size spectrum of precipitation elements can now be measured at all levels, and it seems likely that it will soon be possible to obtain reasonably complete cross-sections of particle distributions in frontal systems, and study the way they are developing to produce the rainfall observed at the surface.

The discussion took a new and interesting turn when Dr. T. W. Wormell (Cavendish Laboratory, Cambridge) described the results of recent work on electrification processes associated with precipitation near the ground.

The introduction of conducting particles, cloud particles or precipitation elements, disturbs the normal ionic equilibrium in the atmosphere and the particles may acquire considerable charges. The importance of such processes has been emphasized of late by Ross Gunn. In the presence of an electric field, and of droplets with appreciable fall-velocities, other effects of selective capture are likely to be of greater importance.

Once precipitation has started, the effects of splashing may seriously affect electrical observations at the ground and, indeed, cause difficulties in any type of observations. Recent work by Adkins at Cambridge has emphasized the importance of such effects; there may be copious production of ions at the ground and a rapid vertical variation of field in the lowest layers of the atmosphere. Further, laboratory work by Hon, also at Cambridge, showed that the continuous splashing of distilled water on many types of target builds up a space-charge of negative large ions which, if not removed, completely alters the effect attending subsequent individual splashing processes.

During quasi-steady rain the electrical effects are often feeble, being comparable in intensity with those of fine weather. According to a recent systematic study by Chalmers, the typical effect in such conditions is a negative potential gradient near the ground accompanied by a downward total current (convection current on rain plus ionization current). In other words, the total current into the ground is in the reverse direction to the ionization current. Chalmers suggests that there is in the upper part of a nimbo stratus cloud some electrification process which gives the top of the cloud a positive charge, with a negatively charged region beneath; and a second process lower down, beneath the freezing. level. Dr. Wormell suggested that this second process might be due to splashing at the ground and turbulent diffusion upwards of a negative space charge on slow moving ions. The electrification in the upper part of a nimbo stratus cloud is of the same sign as the main electrification of a cumulo nimbus, and it is conceivable that the mechanism is the same. It has been common of recent years to assume that this process involves ice. Processes which have been discussed include riming, glaze ice formation and the friction or violent collision of ice particles with different electrical properties. On the other hand, the writings of C. T. R. Wilson and Vonnegut demand a reconsideration of the possibility of influence mechanisms, and the common assumption that a thunderstorm necessarily contains ice in its upper portion has been challenged.

Dr. Wormell felt that the nature of the predominant charging mechanism in thunder clouds is still far from settled, that we still lack the information necessary to make a reliable quantitative assessment of the ice processes, particularly in the presence of an electric field, and that influence mechanisms cannot yet be finally dismissed.

The meeting owed much to excellent arrangements made by the staff of the Department of Natural Philosophy, who were very generous hosts.

B. J. Mason

\section{HILL CLIMATE}

$\mathrm{O}$ $\mathrm{N}$ the second morning of its summer meeting held on July 4 and 5 in the Department of Natural Philosophy, University of Glasgow, the Royal Meteorological Society directed its attention to problems of hill weather. The topics discussed were not peculiar to this branch of meteorology, as they included such general considerations as the information we have and how it can be used; the information we need and how it can be obtained; and the correlation of non-meteorological field data with weather or climatic factors.

As the main sink for observations, and the chief source of information, the Meteorological Office is the recipient of most technical and academic requests for help and advice, so it was appropriate that Mr. R. Cranna, of the Edinburgh Office, should provide the introductory paper on "Problems of Hill Climate". He quoted a number of examples to show that, apart from water balance and land utilization studies, many specific inquiries were being received which could not be adequately answered. Looking further ahead, water supply seemed to be emerging as a limiting factor in industrial development, and he foresaw that light industry might have to move to where water is available, in which event the Meteorological Office would find itself with a much bigger demand for information about hill climate. These inquiries would be for detailed wind and temperature data for 